\title{
Improving Willingness to Pay Estimates for Quality Improvements through Joint Estimation with Quality Perceptions ${ }^{1}$
}

\author{
John C. Whitehead ${ }^{2}$ \\ Associate Professor \\ Department of Economics \\ Appalachian State University \\ Boone, NC 28608-2051
}

December 11, 2003 (Revised March 29, 2005)

\footnotetext{
${ }^{1}$ The author thanks Tom Hoban and Bill Clifford for use of the data and Jeff DeSimone, Mark Holmes, Kelly Maguire, Subhrendu Pattanayak, George Van Houtven, and two anonymous referees for a number of helpful comments and econometric guidance. This paper has also benefited from presentation at the ECU Economics Seminar and LSU Agricultural Center’s “Challenges of Socioeconomic Research in Coastal Systems” 2004 Conference. Support of this research was provided by the U.S. Environmental Protection Agency through Cooperative Agreement CR824861-01-0 with Research Triangle Institute.

2 e-mail: whiteheadjc@appstate.edu; phone: (828)262-6121; fax: (828)262-6105.
} 


\title{
Improving Willingness to Pay Estimates for Quality Improvements through Joint Estimation with Quality Perceptions
}

\begin{abstract}
Willingness to pay for quality change may depend on heterogeneous perceived quality levels. In these instances, contingent valuation studies should include measures of quality perceptions as covariates in the willingness to pay model in order to avoid omitted variable bias. Variation in quality perceptions across respondents leads to a potential endogeneity of quality perceptions. We address the potential for endogeneity bias using an instrumental variables approach in which a measure of quality perceptions is included as a determinant of willingness to pay and is simultaneously determined by various exogenous factors. The willingness to pay model is estimated jointly with quality perceptions allowing for correlation of the error terms. Using data on willingness to pay for water quality improvements in the Neuse River in North Carolina we reject exogeneity of perceived quality. Correcting for endogeneity improves the measurement of willingness to pay by differentiating willingness to pay among respondents with heterogeneous quality perceptions.
\end{abstract}

JEL Classification: Q51, Q53 


\section{Introduction}

The contingent valuation method (CVM) is a stated preference approach to the measurement of the value of changes in the allocation of non-market environmental and natural resources (Mitchell and Carson, 1989). The CVM has clear advantages when compared to revealed preference methods in which actual behavior is used to develop estimates of value (e.g., hedonic price method, travel cost method). Stated preference methods are most useful when an ex-ante policy analysis must consider proposals that are beyond the range of historical experience. The CVM is more flexible than the revealed preference methods, allowing the estimation of the impacts of a wide range of policies. The CVM can be used to estimate non-use values (i.e., passive use values) and ex-ante willingness to pay under uncertainty (Whitehead and Blomquist, forthcoming).

Several issues indicate that the CVM is not a flawless approach to measuring environmental values for policy analysis. ${ }^{3}$ The methodological challenges include the potential for hypothetical bias, temporal bias, sensitivity of willingness to pay estimates to multi-part policy (i.e., embedding, sequencing), and the bias of a reliance on willingness to pay, relative to willingness to accept questions, when the appropriate property rights are held by the respondent (Whitehead and Blomquist, forthcoming). Hoehn and Randall (1987) define a "satisfactory benefit cost indicator" as one that does not overstate the present value of net benefits of policy. More methodological research is needed before we can conclude that the CVM estimates of willingness to pay are satisfactory benefit-cost indicators. For example, if willingness to pay suffers from hypothetical bias benefits will be overestimated. Nevertheless, the CVM (and other

${ }^{3}$ See the symposium on the contingent valuation method in the Fall 1994 issue of the Journal of Economic Perspectives. 
stated preference approaches) are the only option for estimation of the benefits of a broad range of policy questions.

This paper addresses a potential problem where willingness to pay statements are based on subjective perceptions about the environmental quality change instead of the objective change that is prescribed by the policy. In this case, willingness to pay may be biased if the subjective change in quality diverges from the objective change. We argue that standard attempts to control for this divergence may fail. An alternative instrumental variables approach is introduced that may improve the accuracy of willingness to pay estimates.

In the next section we describe the relationship between willingness to pay and quality perceptions and the potential empirical problem. Next, the empirical willingness to pay model is formally described. The survey used to collect the data and the data used to implement the model are then described. The application is to water quality improvements in the Neuse River, North Carolina. Empirical results using two different quality measures are presented. Conclusions and suggestions for future research follow.

\section{Willingness to Pay and Quality Perceptions}

The theoretical construction of willingness to pay for quality improvement shows that willingness to pay is a function of pre-policy and post-policy quality levels, among other variables (Whitehead, 1995). CVM surveys should carefully describe both quality levels and ask

for respondent willingness to pay for the change in quality (Mitchell and Carson, 1989). A crucial assumption is that respondents are valuing the objective quality change that the survey asks them to value. This assumption may not hold in many applications, especially those in which one or both quality levels are not explicitly described and when heterogeneous 
respondents have varying levels of prior information about the quality change.

For example, in a well-funded study that employed in-person interviews Carson and Mitchell (1993) thoroughly describe baseline national water quality as "not boatable” and improved water quality as "boatable, fishable, and swimmable" using visual aids and extensive text. In contrast, many CVM research budgets are not adequate to pursue extensive descriptions of existing quality and changes in quality. With smaller research budgets that may lead to mail or telephone interviews, important text detailing the environmental quality change may be discarded. For example, in the CVM application presented here respondents are asked to value a water quality improvement from the current water quality level to a water quality level that is fishable, swimmable, and drinkable. The current water quality is not explicitly described to respondents during the telephone interview. We rely on existing respondent knowledge about current water quality.

Heterogeneous respondents may have varying subjective perceptions about the current environmental quality level and the hypothetical changes described during the CVM interview. This may be true even when current quality and the quality change are thoroughly described, as in Carson and Mitchell (1993); but it is especially true when the quality change is not explicitly described and assuming that perceptions about quality are homogeneous. In the current application, some might consider current water quality to be too poor for fishing and swimming. Other respondents might consider current water quality to be fishable but not swimmable. With either explicitly described quality change or implicitly understood quality change, CVM questions elicit willingness to pay values that may vary based on differences in respondent quality perceptions. The variation in willingness to pay due to the variation in quality perception 
will not be accounted for by the researcher who ignores the differences in quality perceptions across respondents, adding to the error of the willingness to pay estimates.

Ignoring the divergence between perceived quality and objective quality (i.e., quality as described in the survey) in empirical models of willingness to pay leads to the well-known omitted variable problem. For examples of studies that may suffer from omitted variables problems, Hurley, Otto, and Holtkamp (1999) estimate the willingness to pay for delaying nitrate contamination in drinking water and Stumborg et al. (2001) estimate the willingness to pay for a reduction in phosphorus pollution in lakes. In both cases the perceived quality change is likely to vary across respondents. Neither of these studies includes measures of attitudes or perceptions about the pollution problem in their models of willingness to pay. These omitted variables may cause bias in the estimates of coefficients on variables that are correlated with perceived environmental quality. More generally, omitted variable bias may help explain some poor results from CVM research such as poor fits and even unexpected signs.

One solution to the omitted quality variable problem is to include a proxy variable for quality in the model. In the case of willingness to pay for quality improvements the approach is to elicit perceived quality, or variables that may be related to quality (e.g., attitudes, satisfaction ratings), from survey respondents and include these measures as determinants of willingness to pay. Many CVM studies have followed this approach. For example, Kwak, Lee, and Russell (1997) and Yoo and Yang (2002) measure status quo drinking water quality with scale variables measuring "the respondent's attitude toward current tap water quality" and "degree of satisfaction the respondent has with current tap water quality.” Both studies find that as the proxy for current drinking water quality increases willingness to pay decreases. 
Most studies that include quality perceptions in the willingness to pay model ignore the fact that varying subjective quality perceptions are due to the heterogeneity of respondents and the information and attitudes that they bring to the CVM survey. In contrast, Danielson et al. (1995) estimate the determinants of perceived air and water quality and find that they depend on demographics, environmental knowledge, and environmental attitudes. This approach illustrates a problem with including quality perceptions in willingness to pay models. Quality perceptions may be affected by the same unobserved characteristics that influence willingness to pay. If unobserved tastes are correlated with both perceived quality and willingness to pay the coefficient on the quality perception variable will be biased in a willingness to pay regression model. The bias is due to the correlation in the error terms in the willingness to pay and quality perceptions models. Including the perceived quality variable without accounting for the correlation in the error terms will cause the perceived quality variable and the willingness to pay error term to be correlated, biasing the coefficient on the quality variable.

\section{Model}

The empirical willingness to pay model for a quality improvement that leads to a constant improved quality is

$$
W T P_{i}=\alpha^{\prime} X_{1 i}+\beta q_{i}+\varepsilon_{1 i}
$$

where $\alpha$ is a coefficient vector, $\beta$ is a lone coefficient, $X_{1 i}$ is a vector of independent variables including a constant, income, and other variables that may affect willingness to pay, and $q_{i}$ is perceived current quality, $i=1, \ldots, \mathrm{n}$ individuals. Omission of the current quality variable results in the following model 


$$
W T P_{i}=\alpha^{\prime} X_{1 i}+e_{1 i}
$$

where the new error term, $e_{1 i}=\beta q_{i}+\varepsilon_{1 i}$, is not independent of the explanatory variables if perceived quality is correlated with any of the elements of the $X_{1 i}$ vector, violating one of the classical assumptions of regression analysis. This violation will cause bias in the coefficients on the variables of $X_{1 i}$ that are correlated with perceived quality.

Including perceived quality as an independent variable can potentially cause endogeneity bias. The current level of quality is a subjective measure of quality that varies across individuals, $q_{i}$. Quality can be explained by the model

$$
q_{i}=\gamma^{\prime} X_{2 i}+\varepsilon_{2 i}
$$

where $\gamma$ is a coefficient vector, $X_{2 i}$ is a vector of variables that explain the variation in perceived quality, and $\varepsilon_{2 i}$ is a normally distributed error term.

Substitution of equation (3) into equation (1) yields

$$
W T P_{i}=\alpha^{\prime} X_{1 i}+\beta\left(\gamma^{\prime} X_{2 i}+\varepsilon_{2 i}\right)+\varepsilon_{1 i}
$$

If the same unobserved factors influence both perceived quality and willingness to pay the correlation in error terms will cause correlation in the quality variable and the error term in the willingness to pay model. The correlation will bias the coefficient on quality, $\beta$. Positive correlation will bias the coefficient upwards while negative correlation will bias the coefficient downwards. 
An instrumental variables technique can be used to avoid the endogeneity bias. In the application described below the willingness to pay variable is continuous and censored at zero

(5) $\quad W T P=\left\{\begin{array}{cll}W T P^{*} & \text { if } & W T P^{*}>0 \\ 0 & \text { if } & W T P^{*} \leq 0\end{array}\right.$

where $W T P^{*}$ is the unobserved true willingness to pay. In this case the Tobit model is appropriate. The testing and correction for endogeneity bias is implemented with a simultaneous equations model in which quality and willingness to pay are jointly estimated

$$
\begin{aligned}
W T P_{i} & =\alpha^{\prime} X_{1 i}+\beta q_{i}+\varepsilon_{1 i} \\
q_{i} & =\gamma^{\prime} X_{2 i}+\varepsilon_{2 i} \\
\rho & =\operatorname{corr}\left[\varepsilon_{1 i}, \varepsilon_{2 i}\right]
\end{aligned}
$$

The estimation method is full information maximum likelihood allowing for correlation in the normally distributed error terms, $\rho$. The test for the exogeneity of $q_{i}$ in the independent willingness to pay model is a t-test for $\rho=0$. The model is described in Smith and Blundell (1986) and estimated with the LIMDEP econometric software (Greene, 2002).

The variables in the $X_{2 i}$ vector but not in the $X_{1 i}$ vector are the identifying variables. These variables should have high explanatory power in the instrumenting (i.e., quality) equation and low correlation with willingness to pay and its error term. We test this last condition with a Bassman-type identification test. We regress the error terms from the jointly estimated willingness to pay model on all of the explanatory variables

(7) $\quad \hat{\varepsilon}_{1 i}=\delta^{\prime} X_{2 i}+v_{i}$ 
where $\hat{\varepsilon}_{1 i}$ are the residuals from the willingness to pay regression, $\delta$ is a vector of coefficients and $v_{i}$ is a normally distributed error term. The test statistic is the product of the sample size and the $\mathrm{R}^{2}$ value and is distributed chi-squared with degrees of freedom equal to the number of variables in the $X_{2 i}$ vector, $j$, minus the number of variables in the $X_{1 i}$ vector, $k$, minus 1

$$
\chi^{2}=n \times R^{2}(\text { d.f. }=j-k-1)
$$

If the test statistic is less than the critical value then we conclude the model is properly identified.

\section{Data}

The data is from a 1998 "landowner survey to evaluate implementation of best management practices” in the Neuse River basin in North Carolina (Hoban and Clifford, 1999). A stratified random sample telephone survey of landowners from the 12 counties of the upper, middle, and lower Neuse River basin was employed. All summary statistics and empirical results are weighted to reflect the geographic and farm/non-farm stratification of the sample. The telephone survey response rate (completions divided by completions plus refusals) is $75 \%$. After deleting cases with missing data on variables used in this study the sample size is 663 for a 48.7\% useable response rate.

Survey respondents are presented with the contingent valuation scenario: "We already pay for government environmental programs through taxes, water bills, and other means. However, government will need more money if water quality in the Neuse River is to be protected. This money would pay for government programs to control pollution, monitor water quality, protect fish habitat, and educate people about ways to reduce pollution. The goal would 
be to make sure water quality in the Neuse River is safe enough for fishing, swimming, and drinking treated water from the River.” A popular approach for eliciting willingness to pay is the dichotomous choice (DC) question. With a DC question respondents are asked whether they would be willing to pay a randomly assigned dollar amount (e.g., \$A1) for the improvement in quality. This single question is relatively easy to answer but provides a limited amount of information about willingness to pay. The DC valuation question in this study is: "Would you and your household be willing to pay $\$ A 1$ each year for these programs, if you knew the money would be used to make sure water quality in the Neuse River is safe?" The randomly assigned dollar, hereafter tax, amount in the first willingness to pay question (A1) took on nine values with a random start ranging from $\$ 10$ to $\$ 200$. The tax amounts were pre-tested to determine if the range covered the expected range of willingness to pay. ${ }^{4}$

Follow-up iterative bidding (IB) DC questions with the next highest or lowest tax amount provide more information about willingness to pay. When respondents change their answer in response to a change in the tax (e.g., yes/no, no/yes) the responses are used to construct upper and lower bounds for individual willingness to pay and the continuous willingness to pay variable is measured at the midpoint between the bounds. For respondents who are not willing to pay $\$ 10$, willingness to pay is equal to the response to the follow-up question: "What is the most that you and your household would be willing to pay each year for these programs?” For

\footnotetext{
${ }^{4}$ A crucial test of internal validity of DC willingness to pay is the relationship between the respondent's willingness to pay the cost of the policy and the magnitude of the cost. As the cost rises, the proportion of respondents willing to pay should fall. The first yes/no responses in this application pass this crucial validity test. These results are available from the author.
} 
respondents who are willing to pay $\$ 200$ the willingness to pay variable is conservatively topcoded at $\$ 200 .^{5,6}$

${ }^{5}$ In this paper we use the IB willingness to pay since it facilitates the joint estimation of willingness to pay and quality perceptions with existing econometric software (Greene, 2004). Whitehead, Hoban and Clifford (2001) find some evidence that the IB data may be preferred over DC data in terms of eliciting valid WTP estimates. The IB approach, however, introduces two types of bias that typically drive willingness to pay estimates downward: anchoring (i.e., starting point bias) and incentive incompatibility (e.g., Whitehead, Hoban and Clifford, 2001; Whitehead, 2002). We urge caution upon those researchers who may be considering a benefit transfer exercise with the willingness to pay estimates.

${ }^{6}$ The mid-point method for assigning values within willingness to pay intervals can lead to biased coefficient and willingness to pay estimates if the midpoint values are not equal to the expected value of willingness to pay. Cameron and Huppert (1989) use the interval data model and show the bias that results when the data obtained from the mid-point method is used with ordinary least squares regression. The choice of empirical model in this study depends on conflicting aspects of these data. The wider the intervals the greater chance of bias if interval regression is not used. The greater the ratio of zero willingness to pay values to positive willingness to pay values the greater chance of bias if Tobit regression is not used. These data contain a high ratio of zero values and relatively narrow intervals so we proceed with the Tobit model. Using similar data, Whitehead, Hoban, and Clifford (1995) find only minor differences 
The average maximum willingness to pay for the quality improvement, $M A X W T P$, is $\$ 76$ (Table 1). The largest group of respondents is willing to pay zero (29\%). The next largest groups of respondents are willing to pay $\$ 62.50$ (15\%), \$112.50 (12\%), and \$200 (11\%). In the other categories, $17 \%$ are willing to pay between zero and $\$ 37.50$, about $11 \%$ are willing to pay between $\$ 137.50$ and $\$ 187.50$, and 5\% percent are willing to pay $\$ 87.5$.

We use two water quality perception variables to implement the model. The first is the general question (WQRATE): "When you think of water quality please consider its suitability for various uses (such as swimming, fishing, or drinking). Would you say it is excellent, good, fair, or poor?” The second quality variable is specific to drinking water (WQDRINK): “How would you rate the quality or purity of your home drinking water as it comes from the faucet? Would you say it is excellent, good, fair, or poor?” For each of the water quality variables the scale variable is increasing in quality. "Excellent” water quality is coded at 4, "good” is coded at 3, “fair" is 2 and "poor" is 1 . Forty-two percent consider general water quality to be fair, $41 \%$ consider it good, and 13\% consider it poor. Only 4\% consider general water quality excellent. Fifty-one percent rate drinking water quality good, 26\% rate it excellent, 19\% rate it fair, and only $4 \%$ rate it poor.

Several dummy variables measure the respondent's proximity to water and water-related problems (Table 1). RURAL is equal to one if the respondent's home is in a rural area. SEPTIC is equal to one if the respondent's home has a septic tank. PRIVWELL is equal to one if the respondent gets its water from a private well. PROPERTY is equal to one if the respondent's

between coefficient estimates and willingness to pay values between the Tobit and interval regression models. 
property is located next to any rivers, streams, or other bodies of water.

Dummy variables measure whether the respondent has heard of the term watershed (WATERSHD), nonpoint source pollution (NONPOINT), and Pfiesteria (PFIESTER). Several socioeconomic variables are included in the analysis. NONWHITE is equal to one if the respondent is “black,” “American Indian,” “Asian,” “Mixed Race” and equal to zero if “white.” FEMALE is equal to one if the respondent is female, AGE is the age of the respondent, FARM is equal to one if the respondent is part of the farm sample, and INCOME is the respondent's family income (in thousands of 1997 dollars).

\section{Results}

We estimate independent and joint quality/willingness to pay models for the two quality variables. We use all exogenous variables as instrumental variables in the $X_{2 i}$ vector. Quality is specified to depend on the tax amount, income, knowledge, water-related, and socioeconomic variables. We have no a priori expectations of the signs of the coefficients in the quality model. The demographic variables are excluded in the $X_{1 i}$ vector and serve as the identifying variables. We choose these demographic variables as the identifying variables because they are strongly related to perceived quality and unrelated to willingness to pay. The willingness to pay equation is specified to depend on the tax amount, income, knowledge, water-related variables, and perceived quality.

The coefficient on the tax amount will be statistically significant if the data is subject to 
starting point bias. ${ }^{7}$ The coefficient on INCOME will be positive (negative) if quality is a normal (inferior) good. The coefficient on the quality variable is expected to be negative; higher perceived quality leads to lower willingness to pay for quality improvements. We have no a priori expectations for the signs of the other coefficients in the willingness to pay model.

\section{General Water Quality}

Perceived general water quality (WQRATE) increases with income and if the respondent gets their drinking water from a private well (Table 2). Perceived water quality is lower if the respondents' property is located near water or if they had heard of the term watershed. No other coefficient on the independent variables is statistically significant. The model has low explanatory power.

In the independently estimated willingness to pay model, the coefficient on the tax amount is statistically different from zero indicating starting point bias. The coefficient on income indicates that quality is a normal good and provides evidence of the internal validity of

${ }^{7}$ If the respondent anchors his or her answers to the follow-up valuation questions because of the perception that the first tax amount is "about right" or for some other reason then the final willingness to pay estimate is biased towards the starting tax amount. Anchoring will upwardly (downwardly) bias the willingness to pay estimate if the average of the starting tax amounts is greater (lower) than the sample's true willingness to pay value (Whitehead, Hoban, and Clifford, 1995). Since the tax amount is randomly assigned and not correlated with other independent variables, starting point bias will not affect the results that are the focus of this paper. 
willingness to pay. Willingness to pay is lower for rural respondents and higher for those with property near water. General perceived water quality is not a factor affecting willingness to pay. One conclusion with the independent model would be that the willingness to pay estimate lacks validity due to the statistical insignificance of the coefficient on the quality variable.

Next the water quality and willingness to pay models are jointly estimated. In the water quality model most of the coefficients retain their statistical significance. The coefficient on PROPERTY is no longer statistically significant. Those who are older perceive higher quality when the model is jointly estimated. In the willingness to pay equation the coefficients on RURAL and PROPERTY are no longer statistically significant. Most importantly, the coefficient on WQRATE is negative and statistically significant, as expected. This indicates that as perceived general water quality increases the willingness to pay for improved water quality decreases. The joint model provides evidence that the willingness to pay estimate has some degree of internal validity; in other words, willingness to pay passes a scope test.

The correlation of the error terms in the willingness to pay and quality equations, $\rho$, is positive and statistically different from zero indicating that the perceived water quality variable is endogenous in the independently estimated willingness to pay equation. The positive correlation is consistent with the upwardly biased coefficient on water quality in the independently estimated model. The result from the Bassman-type test indicates that the joint model is appropriately identified ( $\chi^{2}=7.48[3$ d.f.], $p=.05$ ).

\section{Drinking Water Quality}

In contrast to the paucity of statistically significant coefficients in the WQRATE model, 
seven of the thirteen variables have significant coefficients in the drinking water quality model (Table 3). Perceived drinking water quality is higher for rural respondents, and if the respondent gets their drinking water from a private well. Quality increases with age and for farm residence. Perceived water quality is lower if the respondent is on a septic tank and if the respondents' property is located near water. Those who are nonwhite perceive lower water quality.

In the independently estimated willingness to pay model, the coefficient on the tax amount indicates starting point bias and the coefficient on income indicates that quality is a normal good. Willingness to pay is lower for rural respondents and higher for those with property near water. Drinking water quality has a small negative effect on willingness to pay.

In the jointly estimated quality equation most of the coefficients retain their statistical significance. The coefficients on SEPTIC and NONWHITE are no longer statistically significant. Those with higher incomes and who have heard about Pfiesteria perceive higher water quality. Female respondents perceive lower water quality when the model is jointly estimated. In the willingness to pay equation the coefficients on RURAL and PROPERTY are no longer statistically significant. Those who get their drinking water from a private well are willing to pay more. Those who have heard of the terms Pfiesteria and watershed are willing to pay more. Again, the income effect provides evidence of the internal validity of willingness to pay. Most importantly, the coefficient on WQDRINK is negative and statistically significant. This indicates that as perceived drinking water quality increases the willingness to pay for improved water quality decreases, as expected. The scope test in the joint model provides evidence that the willingness to pay estimate has some degree of internal validity.

The correlation of the error terms in the willingness to pay and quality equations is 
statistically different from zero indicating that the perceived water quality variable is endogenous in the independently estimated willingness to pay equation. The positive correlation is consistent with the upwardly biased coefficient on water quality in the independently estimated model. The result from the Bassman-type identification test indicates that the joint model is appropriately identified $\left(\chi^{2}=7.13[3\right.$ d.f.], $p=.05)$.

\section{Willingness to Pay}

Expected willingness to pay estimates are constructed for each of the jointly estimated quality models (Table 4). ${ }^{8}$ Willingness to pay is assessed at each of the four perceived water quality levels. In the WQRATE model, willingness to pay decreases from $\$ 288$ to $\$ 0$ as baseline water quality perceptions increase from “poor” to “excellent.” Willingness to pay falls from \$254 to $\$ 19$ as drinking water quality perceptions increase from "poor" to "excellent" in the WQDRINK model. The range of expected willingness to pay estimates is large and differences are economically significant with the more appropriate jointly estimated quality and willingness to pay model. In contrast, the range of willingness to pay estimates from the independently estimated models is less than $\$ 50$ because the quality coefficients are either statistically

\footnotetext{
${ }^{8}$ The expected willingness to pay value is $E(W T P)=\Phi(Z)\left(\alpha^{\prime} \bar{X}_{1}+\beta \bar{q}+\sigma \lambda\right)$,
} where $Z=\frac{\alpha^{\prime} \bar{X}_{1}+\beta \bar{q}}{\sigma}, \lambda=\frac{\phi(Z)}{\Phi(Z)}, \phi(\cdot)$ is the standard normal density function, $\Phi(\cdot)$ is the standard normal distribution function, and $\sigma$ is the standard error of $\varepsilon_{1 i}$. Expected willingness to pay is evaluated at the means of the independent variables, $\bar{X}_{1}$ and $\bar{q}$. The standard errors are constructed using the Delta Method (Greene, 1997). 
insignificant or biased upward. Using the inappropriate independently estimated willingness to pay models would lead to a reduction in the policy-relevant magnitude of the effect of quality on willingness to pay.

\section{Conclusions}

Our results indicate that the endogeneity of quality perceptions in willingness to pay models is a potential econometric problem. The coefficients on quality variables are biased in independently estimated willingness to pay models that do not account for endogeneity. In jointly estimated willingness to pay models, current quality has negative effects on willingness to pay as expected. In other words, respondents who perceive that current water quality is "poor" are willing to pay more for a quality improvement than those who think current water quality is "fair" or better.

Policy analysts require benefit estimates that correspond to the true, or objective, change in resource allocation (e.g., quality) that will result from the policy or program. One problem that most CVM research faces is that an attempt is made to describe the objective quality change to respondents, yet willingness to pay statements are made based on subjective quality. Willingness to pay estimates from CVM research would be improved if adjustments can be made so that subjective willingness to pay is consistent with objective willingness to pay.

CVM researchers should consider the implications of omitted variable bias and endogeneity bias whenever quality or other changes are to be valued by respondents and there is the potential for a divergence between perceptions and reality. For example, this issue might be especially important for environmental amenities that generate non-use values and for which 
respondents are not familiar (e.g., preservation of the Artic National Wildlife Refuge). Modeling the endogeneity of the change in the resource allocation might especially be important when environmental risk is considered. There is much research that finds a divergence between subjective and objective risks (e.g., Viscusi, 1989). Identification of situations with divergence between subjective and objective risks is important for policy analysis. Valuation of these risks should consider their subjectivity and potential endogeneity.

Future research should begin with a survey design focused on explicit descriptions of preand post-policy quality perceptions, their determination and the relationship between quality perceptions and willingness to pay. Also, future research should consider joint estimation of quality perceptions and the theoretically preferred dichotomous choice willingness to pay. Another avenue for future research is the role of information in minimizing the divergence between subjective and objective quality and risks. Information provision in the survey instrument can lead to improvements in the accuracy of willingness to pay as subjective quality converges with objective quality (Blomquist and Whitehead, 1998; Hoehn and Randall, 2002). Variations in information treatments could be used to determine the type of survey information that would make explicit modeling of quality and risk change unnecessary. These extensions should help determine when joint estimation is necessary. 


\section{References}

Blomquist, Glenn C. and John C. Whitehead, “Resource Quality Information and Validity of Willingness to Pay in Contingent Valuation,” Resource and Energy Economics, 20, 179196, 1998.

Cameron, Trudy Ann and Daniel D. Huppert, “OLS versus ML Estimation of Non-market Resource Values with Payment Card Interval Data,” Journal of Environmental Economics and Management, 17, 230-246, 1989.

Carson, Richard T., and Robert Cameron Mitchell, “The Value of Clean Water: The Public’s Willingness to Pay for Boatable, Fishable, and Swimmable Quality Water,’ Water Resources Research, 29, 7, 2445-2454, 1993.

Danielson, Leon, Thomas J. Hoban, George Van Houtven, and John C. Whitehead, "Measuring the Benefits of Local Public Goods: Environmental Quality in Gaston County, North Carolina" Applied Economics, 27, 1253-1260, 1995.

Greene, William H., Econometric Analysis, $3^{\text {rd }}$ Edition, Prentice Hall, 1997.

Greene, W.H., LIMDEP Version 8.0: User's Manual, Econometric Software, Bellport, N.Y., 2002.

Hoban, Thomas J. and William B. Clifford, "Landowners' Knowledge, Attitudes, and Behavior in The Neuse River Watershed," Final Report to the United States Environmental Protection Agency and the North Carolina Department of Environment and Natural Resources, 1999. 
Hoehn, John P., and Alan Randall, “A Satisfactory Benefit Cost Indicator from Contingent Valuation,” Journal of Environmental Economics and Management, 14, 226-47, 1987.

Hoehn, John P. and Alan Randall, “The Effect of Resource Quality Information on Resource Injury Perceptions and Contingent Values,” Resource and Energy Economics, 24, 13-33, 2002.

Hurley, Terrance M., Daniel Otto, and Janie Holtkamp, “Valuation of Water Quality in Livestock Regions: An Application to Rural Watersheds in Iowa,” Journal of Agricultural and Applied Economics, 177-184, April 1999.

Kwak, Seung-Jun, Junsoo Lee and Clifford S. Russell, “Dealing with Censored Data from Contingent Valuation Surveys: Symmetrically-Trimmed Least Squares Estimation,” Southern Economic Journal, 63, 743-750, 1997.

Mitchell, Robert Cameron, and Carson, Richard T., Using Surveys to Value Public Goods: The Contingent Valuation Method, Resources for the Future, Washington, D.C., 1989.

Smith, R., and R. Blundell, “An Exogeneity Test for a Simultaneous Equation Tobit Model with an Application to Labor Supply,” Econometrica, 54, 679-685, 1986.

Stumborg, Basil E., Kenneth A. Baerenklau, and Richard C. Bishop, "Nonpoint Source Pollution and Present Values: A Contingent Valuation Study of Lake Mendota," Review of Agricultural Economics, 23, 120-132, 2001.

Viscusi, W. Kip, "Prospective Reference Theory: Toward an Explanation of the Paradoxes," Journal of Risk and Uncertainty, 2, 235-263, 1989. 
Whitehead, John C., "Willingness to Pay for Quality Changes: Comparative Statics and Theoretical Interpretations of Empirical Results,” Land Economics, 71, 207-215, 1995.

Whitehead, John C., "Incentive Incompatibility and Starting-Point Bias in Iterative Valuation Questions, Land Economics, 78, 285-297, 2002.

Whitehead, John C., and Glenn C. Blomquist, "Contingent Valuation and Benefit-Cost Analysis,” in Anna Alberini and James Kahn, editors, Handbook of Contingent Valuation, Cheltenham, U.K.: Edward Elgar Publishing, forthcoming.

Whitehead, John C., Timothy C. Haab, and Ju-Chin Huang, "Part-Whole Bias in Contingent Valuation: Will Scope Effects Be Detected with Inexpensive Survey Methods?" Southern Economic Journal, 65, 160-168, 1998.

Whitehead, John C., Thomas J. Hoban, and William B. Clifford, "Measurement Issues with Iterated, Continuous/Interval Contingent Valuation Data,” Journal of Environmental Management, 43, 129-139, 1995.

Whitehead, John C., Thomas J. Hoban, and William B. Clifford, "Willingness to Pay for Agricultural Research and Extension Programs,” Journal of Agricultural and Applied Economics, 33, 91-101, 2001.

Yoo, Seung-Hoon and Hee-Jong Yang, "Application of Sample Selection Model to DoubleBounded Dichotomous Choice Contingent Valuation Studies,” Environmental and Resource Economics, 20, 147-163, 2001. 
Table 1. Data

\begin{tabular}{|c|c|c|c|}
\hline Variable & Description & Mean & Std.Dev. \\
\hline MAXWTP & Maximum willingness to pay (1998 dollars) & 75.95 & 70.57 \\
\hline WQRATE & Perception of general water quality & 2.46 & 0.73 \\
\hline WQDRINK & Perception of drinking water quality & 3.03 & 0.82 \\
\hline A1 & Randomly assigned tax amount & 103.13 & 62.44 \\
\hline INCOME & Family income (in thousands, 1997 dollars) & 71.29 & 61.50 \\
\hline RURAL & 1 if rural resident & 0.52 & 0.50 \\
\hline SEPTIC & 1 if has septic tank & 0.64 & 0.48 \\
\hline PRIVWELL & 1 if gets water from private well & 0.41 & 0.49 \\
\hline PROPERTY & 1 if property is near water & 0.37 & 0.48 \\
\hline NONPOINT & 1 if heard of nonpoint source pollution & 0.16 & 0.37 \\
\hline PFIESTER & 1 if heard of Pfiesteria & 0.77 & 0.42 \\
\hline WATERSHD & 1 if heard of watershed & 0.77 & 0.42 \\
\hline NONWHITE & 1 if nonwhite & 0.14 & 0.35 \\
\hline FEMALE & 1 if female & 0.43 & 0.49 \\
\hline AGE & age & 51.09 & 14.75 \\
\hline FARM & 1 if family owns farm & 0.35 & 0.48 \\
\hline Cases & 663 & & \\
\hline
\end{tabular}


Table 2. Willingness to Pay and Quality Models: WQRATE Independent

Joint

WQRATE

MAXWTP

WQRATE

MAXWTP

Coeff. t-ratio Coeff. t-ratio Coeff. t-ratio Coeff. t-ratio

ONE

$\begin{array}{llllllll}2.416 & 14.94 & 18.608 & 1.08 & 2.298 & 15.66 & 403.223 & 2.65\end{array}$

A1

$0.000 \quad 0.94$

0.309

$5.54 \quad 0.000$

0.77

0.351

3.86

INCOME

$0.001 \quad 2.26$

0.110

$1.88 \quad 0.001$

3.04

0.305

2.61

RURAL

$-0.054-0.65$

$-29.094$

$-3.00$

$-0.058$

$-0.70$

$-24.114 \quad-1.42$

SEPTIC

$-0.021--0.24$

15.366

$\begin{array}{lll}1.42 & -0.084 & -0.94\end{array}$

4.055

0.20

PRIVWELL

0.311

4.51

$-11.966$

$-1.38$

0.284

4.13

32.140

1.34

PROPERTY

$-0.143-2.43$

22.519

3.07

$-0.090 \quad-1.51$

5.333

0.39

NONPOINT

$0.040 \quad 0.49$

$-4.702$

$-0.48$

$-0.012 \quad-0.15$

2.715

0.17

PFIESTER

$-0.116 \quad-1.60$

10.530

1.20

$-0.122$

$-1.59$

$-17.168$

$-1.03$

WATERSHD

$-0.121 \quad-1.63$

5.205

0.59

$-0.175$

$-2.36$

$-2.952$

$-0.19$

NONWHITE

$\begin{array}{ll}-0.008 & -0.09\end{array}$

0.018

0.30

FEMALE

$0.046 \quad 0.70$

$-0.059-1.35$

AGE

$0.001 \quad 0.41$

$0.005 \quad 2.62$

FARM

$0.008 \quad 0.10$

0.088

1.62

WQRATE

$\sigma$

$\mathrm{R}^{2}$

0.062

Log Likelihood

$-794.05$

$-2986.97$

$\rho$
$-2.404 \quad-0.49$

$86.383 \quad 28.88$
$-157.301 \quad-2.64$

$83.627 \quad 22.72$

$-2324.45$

$0.800 \quad 2.643$ 
Table 3. Willingness to Pay and Quality Models: WQDRINK

\begin{tabular}{|c|c|c|c|c|c|c|c|c|}
\hline & \multicolumn{4}{|c|}{ Independent } & \multicolumn{4}{|c|}{ Joint } \\
\hline & \multicolumn{2}{|c|}{ WQDRINK } & \multicolumn{2}{|c|}{ MAXWTP } & \multicolumn{2}{|c|}{ WQDRINK } & \multicolumn{2}{|c|}{ MAXWTP } \\
\hline & Coeff. & t-ratio & Coeff. & t-ratio & Coeff. & t-ratio & Coeff. & t-ratio \\
\hline ONE & 2.374 & 14.43 & 40.546 & 2.41 & 2.303 & 15.49 & 257.185 & 3.95 \\
\hline A1 & 0.000 & -0.58 & 0.303 & 5.46 & 0.000 & -0.56 & 0.275 & 3.91 \\
\hline INCOME & 0.001 & 1.60 & 0.115 & 1.97 & 0.001 & 1.64 & 0.169 & 2.33 \\
\hline RURAL & 0.166 & 1.96 & -25.340 & -2.59 & 0.179 & 2.12 & 2.398 & 0.15 \\
\hline SEPTIC & -0.147 & -1.65 & 14.225 & 1.32 & -0.135 & -1.50 & 5.213 & 0.34 \\
\hline PRIVWELL & 0.419 & 5.97 & -7.660 & -0.87 & 0.424 & 5.81 & 32.641 & 2.02 \\
\hline PROPERTY & -0.107 & -1.78 & 21.645 & 2.97 & -0.100 & -1.64 & 12.898 & 1.35 \\
\hline NONPOINT & 0.045 & 0.55 & -3.194 & -0.33 & 0.053 & 0.57 & 9.044 & 0.75 \\
\hline PFIESTER & 0.110 & 1.49 & 11.823 & 1.35 & 0.122 & 1.73 & 20.985 & 1.85 \\
\hline WATERSHD & 0.010 & 0.14 & 7.235 & 0.82 & 0.012 & 0.17 & 19.394 & 1.66 \\
\hline NONWHITE & -0.159 & -1.77 & & & -0.089 & -1.23 & & \\
\hline FEMALE & -0.041 & -0.62 & & & -0.084 & -1.62 & & \\
\hline AGE & 0.006 & 2.99 & & & 0.008 & 3.85 & & \\
\hline FARM & 0.323 & 3.825 & & & 0.258 & 3.477 & & \\
\hline WQDRINK & & & -10.895 & -2.35 & & & -96.147 & -3.89 \\
\hline$\sigma$ & & & 85.989 & 28.89 & & & 84.834 & 22.26 \\
\hline $\mathrm{R}^{2}$ & 0.221 & & & & & & & \\
\hline Log Likelihood & -784.56 & & -2998.65 & & & & -2328.78 & \\
\hline$\rho$ & & & & & & & 0.610 & 3.670 \\
\hline
\end{tabular}


Table 4. Expected Willingness to Pay: Jointly Estimated Models

\begin{tabular}{lcccc} 
& \multicolumn{2}{c}{ WQRATE } & \multicolumn{2}{c}{ WQDRINK } \\
Water Quality & E(WTP) & t-ratio & E(WTP) & t-ratio \\
Poor & 287.83 & 3.23 & 253.57 & 5.12 \\
Fair & 132.65 & 5.14 & 158.45 & 6.52 \\
Good & 21.67 & 1.73 & 72.92 & 19.78 \\
Excellent & 0.41 & 0.32 & 19.22 & 2.23
\end{tabular}

